\title{
Labour market integration and innovation: the implications on consumers
}

\author{
Mehdi Chowdhury \\ Bournemouth University, UK
}

and

Arijit Mukherjee

Nottingham University Business School and CFGE, Loughborough University, UK, CESifo and INFER, Germany, and RCIE, City University of Hong Kong, Hong Kong

Original submission: December 2013

Accepted: August 2015

\begin{abstract}
We show the effects of labour market integration on consumers. Labour market integration allows the firms in the labour recipient countries to hire skilled and unskilled workers at lower wages. If labour market integration creates the possibility of migration of skilled workers, it increases investments in innovation and benefits the consumers. However, if labour market integration creates the possibility of migration of unskilled workers, it neither increases investment in innovation nor benefits the consumers always. Our results suggest that the effects of labour market integration on the consumers depend on several factors such as the market size, differences in the labour coefficients and wage and the type of migrated workers (i.e., skilled or unskilled workers).
\end{abstract}

Key Words: Labour market integration; Skilled and unskilled workers; Innovation; Consumers

JEL Classifications: F15; F22; O31

Correspondence to: Arijit Mukherjee, School of Business and Economics, Sir Richard Morris Building, Loughborough University, Loughborough, Leicestershire, LE11 3TU, UK Email: A. Mukherjee@lboro.ac.uk; Fax: +44-1509-222723

\footnotetext{
We thank three anonymous referees, Bouwe Dijkastra and Bibhas Saha for helpful comments and suggestions. The usual disclaimer applies.
} 


\section{Labour market integration and innovation: the implications on consumers}

\section{Introduction}

An important purpose of economic integration is to reduce the barriers to trade in goods and the factors of production. Many countries are gradually reducing the barriers to the movements of goods and capital, yet the movements of labour - mainly from the developing to the developed countries - are still very much restricted. It is intuitive that labour movements reduce wage and create adverse effects on the substitutable workers in the recipient countries, but they benefit the consumers. While these effects of labour movements got attention in the economics literature (Gaston and Nelson, 2007 and the references therein), they ignore an empirically relevant factor, viz., the effects of labour movements on innovation, which also affects consumer surplus.

The relationship between migration and innovation has been investigated empirically by a number of papers (see, Rashidi and Pyka, 2013 for a review). This literature generally provides a positive effect of migration of skilled workers on innovation due to network (Saxanian et al., 2003) and diversity (Parrotta, 2014). However, similar conclusion may not necessarily apply to unskilled migration. For example, a report by International Organisation for Migration (Platonova and Urso, 2010, page 323) has expressed the view that migration may negatively affect innovation through the availability of cheap labour. A similar view has also been expressed by the Migration Advisory Committee (Migration Advisory Committee, 2013, page 174).

We use a simple model to provide a theoretical explanation for this phenomenon. More specifically, considering an international oligopoly, we analyse the effects of labour market integration on consumers, highlighting its strategic effects on innovation. We show that the effects of labour movement in the presence of innovation are not straightforward, and 
the effects on consumers depend on several factors such as the market size, labour coefficients, wage and the type of migrated workers (i.e., skilled or unskilled workers).

We consider a model with two competing innovating firms from different countries with different wages. We visualise the low-wage country as a developing country and the high-wage country as a developed country. We show the effects of labour market integration on innovation and consumers' welfare, when integration creates the possibility of labour mobility from the low-wage country to the high-wage country. ${ }^{1}$ For a better understanding, we consider two separate cases: (i) when only the firm in the high-wage country innovates and (ii) when only the firm in the low-wage country innovates. This distinction is for understanding the theoretical effects clearly and in no way, we visualise a situation where only the firm from a developing country innovates. In this framework, we show the effects of migration of skilled workers, used for innovation, and unskilled workers, used for production, separately. The effects of innovation by both firms and migration of both skilled and unskilled workers then follow easily from our analysis.

It is worth pointing out that while earlier papers consider innovative activities only in the developed countries (Helpman, 1993 and Lai, 1998), recent empirical evidence shows significant innovative activities in many developing countries also, such as India and China (Unnikrishnan, 2004 and Wei et al., 2008). In different contexts, recent papers have started to focus on the innovative activities of the developing countries (Zhou et al., 2002, Chen and Puttitanun, 2005 and Sinha and Mukherjee, 2013). It is also evident from the data shown in Table 1 that the developing countries are progressing fast in research and development. The leading country in 2013 was China with 704936 applications. About half of the top 15 countries are developing or newly developed countries. What is very interesting is that the countries like China, Korea, India, Brazil, Turkey and Poland exhibit very high growth rate of

\footnotetext{
${ }^{1}$ We observe that, on one hand, firms from Mexico, China, India and Eastern European countries compete in the product markets with firms from the developed countries and, on the other hand, the former countries export skilled and unskilled workers to the developed countries.
} 
patent applications (shown in the last column) compared to the other developed countries like Germany, United Kingdom, France, Italy and Canada. The only exception is United States that exhibits a $19 \%$ growth rate.

\section{Table 1}

Our analysis generates the following results. First, consider the possibility of migration of unskilled workers following labour market integration. If only the firm in the high-wage country innovates, labour market integration may either increase or decrease innovation and consumer surplus depending on the market size, labour coefficients and wage. If only the firm in the low-wage country innovates, labour market integration reduces innovation but it may either increase or decrease consumer surplus depending on the labour coefficients and wage. It is then immediate that labour market integration may either increase or decrease innovation and consumer surplus if both firms innovate.

Now consider the possibility of migration of skilled workers following labour market integration. If only the firm in the high-wage country innovates, labour market integration increases innovation and consumer surplus. If both firms innovate, labour market integration increases (reduces) innovation of the firm in the high-wage (low-wage) country. Since the increase in innovation in the high-wage country is higher than the decrease in innovation in the low-wage country, labour market integration increases consumer surplus. ${ }^{2}$

Our results can be useful for recent policy debates on integration of labour markets. The public opinion in developed countries is now questioning the effects of immigration, specifically in the European Union with reference to the free movement of labour from one member country to another member country. Our results show how the possibility of labour

\footnotetext{
${ }^{2}$ Migration of skilled workers does not occur in our analysis if only the firm in the low-wage country innovates.
} 
migration from a low-wage European country to a high-wage European country may affect the consumers by affecting innovation.

The remainder of the paper is organised as follows. Section 2 reviews the literature. Section 3 describes the model and shows the implications of migration of unskilled workers on innovation and consumers' welfare. Section 4 shows the effects of migration of skilled workers. Section 5 discusses the implications of some of our assumptions and section 6 concludes. Several mathematical calculations are relegated to Appendix.

\section{Literature review}

Our paper is related to the recently growing literature on economic integration and innovation. The existing literature uncovers the relation between product market integration and foreign direct investment (Chen 2009, Haufler and Wooton 2010), trade and welfare (Egger and Larch 2011), trade barriers, innovations and R\&D subsidies (Haaland and Kind 2008, Braun 2008, Impullitti 2010, Long et al. 2011 and Morita 2012). In contrast, we show the effects of labour market integration under endogenous technology choice.

As mentioned in the Introduction, the relationship between labour migration and innovation is getting more attention in recent decades. Lundborg and Segerstrom (2002) used a quality ladder endogenous growth model and showed, by using computer simulation, that migration to the Northern country increases innovation in the North, decreases innovation in the South and reduces the price. In contrast, we show that the possibility of migration following labour market integration may either increase or decrease innovation and price depending on the factors such as the market size, labour coefficients, wage and the type of 
migrated workers (i.e., skilled or unskilled workers). ${ }^{3}$ Our results are due to the strategic effects of labour market integration on innovation.

Kuhn and McAusland (2009) showed the implications of migration of a producer on process innovation or quality of the product and consumers' welfare under segmented markets. In contrast, we consider migration of workers (unskilled workers) and researchers (skilled workers) on innovation and consumers' welfare when the producers do not change their locations.

The linkage between our paper and the recent brain drain literature (See Gibson and McKenzie, 2011; Docquier and Rapoport, 2012 for recent reviews of the literature) is also clearly recognisable. The brain drain literature mainly analyses the economic benefit of migration on the source country. In contrast, we look at the effects on both the source and the recipient countries. Unlike the brain drain literature, which generally considers exogenous technologies, we determine the technologies endogenously. Thus, our analysis gives a clear guidance to the economists and the policy makers dealing with the issues related to integration of labour markets of the developed and developing countries.

Finally, our paper can also be related to Marjit and Mukherjee (2008), which show the effects of outsourcing on the innovation of the outsourcing firm in the developed country. In contrast, we show how labour market integration, creating the possibility of migration of skilled and unskilled workers, affects innovation of the firms from developed and developing countries.

\footnotetext{
${ }^{3}$ Bretchger (2001) also considers innovation and migration in a growth model. However, unlike our paper, where innovation provides know-how to the final goods, innovation in that paper provides know-how to the intermediate goods.
} 


\section{The model}

Consider two countries -1 and 2, with integrated markets. Assume that there is firm 1 in country 1 and firm 2 in country 2 . The firms compete like Cournot duopolists with homogeneous products. We assume that the inverse market demand function is

$$
p=a-\left(q_{1}+q_{2}\right)
$$

where $p$ is the price and $q_{i}$ is the output of firm $i, i=1,2$.

Assume that besides production, the firms also undertake process innovation. We assume for simplicity that both production and innovation require only labour. However, production and innovation require different types of workers. We call the workers in the production as unskilled workers and the workers in innovation as skilled workers. We assume that the respective group of workers are perfect substitutes in both countries, labour supply of each type of worker (i.e., skilled and unskilled) is perfectly elastic in both countries and wages of the unskilled and skilled workers in the $i$ th country, $i=1,2$, are $w_{u i}$ and $w_{s i}$ respectively with $w_{u 1} \geq w_{u 2}$ and $w_{s 1} \geq w_{s 2}$. Hence, country 1 is a high-wage country and country 2 is a low-wage country to start with. Institutional reasons such as a stronger trade union may be the reason for the wage difference.

We assume that firm 1 requires $\theta_{1}$ unskilled workers to produce one unit of the product and firm 2 requires $\theta_{2}$ unskilled workers to produce one unit of the product. Process innovations by the firms reduce labour coefficients in the production process. We assume that if the firms hire more skilled workers for innovation (i.e., investing more in innovation), on one hand, they can reduce the labour coefficients in the production process by a greater extent, but on the other hand, they need to incur higher costs for innovation. Specifically, we assume

that if the $i$ th firm, $i=1,2$, hires $\frac{\left(R_{i}\right)^{2}}{2}$ skilled workers, thus spending $c_{i}\left(R_{i}\right)=\frac{w_{s i}\left(R_{i}\right)^{2}}{2}$ 
amount in innovation, it can reduce the labour coefficient by $b_{i} R_{i}$. Hence, following the tradition of the innovation literature (D'Aspremont and Jacquemin, 1988), we assume that there are diminishing returns to $\mathrm{R} \& \mathrm{D}$ expenditure, which may be due to the cost of coordinating more researchers.

We will consider two situations in the following analysis: (i) the case of no labour market integration, and (ii) the case of labour market integration. We assume that labour market integration creates perfect mobility of workers between the countries and allows firm 1 to hire workers at the low-wage prevailed in country $2 .{ }^{4}$ Perfectly elastic labour supply in country 2 implies that labour market integration does not affect the wage in country 2 . If country 2 is endowed with a large pool of labour force or labour demand in the industry under consideration is not significant relative to the amount of available workers in country 2 , migration of some people from country 2 to country 1 would not have much effect on the wage in country 2 , thus justifying stickiness in wage in country 2 . Hence, labour market integration allows both firms to hire workers at the lower wage prevailed in country 2.

Wages of the unskilled and skilled workers in country 1 are $\alpha_{u} w_{u 1}$ and $\alpha_{s} w_{s 1}$ respectively, where $\alpha_{u}=\alpha_{s}=1$ under no labour market integration, and $\alpha_{u}=\frac{w_{u 2}}{w_{u 1}}$ and $\alpha_{s}=\frac{w_{s 2}}{w_{s 1}}$ under labour market integration. It may be worth noting that wage equality is the artefact of no cost of immigration, which we assume for simplicity. It is immediate that a positive cost of immigration does not equate wage in both countries following labour market integration, although the possibility of migration allows the firm in the high-wage country to hire workers at a lower wage. Our qualitative results hold even if labour market integration does not reduce the high wage all the way to equate it with the low wage.

\footnotetext{
${ }^{4}$ It is intuitive that if the workers in firm 1 demands wages more than what is prevailed in country 2 (the lowwage country), firm 1 would be able to hire workers from country 2 , thus either inducing the workers of country 1 to accept the wage prevailed in country 2 or allowing firm 1 to hire workers from country 2 .
} 
We have assumed constant wages for analytical simplicity. The presence of surplus unskilled workers in many economies may justify a constant wage for unskilled workers. It may not be unreasonable also to assume a constant wage for skilled workers if the number of workers employed in the industry under question is sufficiently small compared to the total number of workers available in the economy.

To show the effects of migration of unskilled and skilled workers, we will consider two cases separately: (i) $w_{u 1}>w_{u 2}$ and $w_{s 1}=w_{s 2}=w_{s}$ and (ii) $w_{u 1}=w_{u 2}=w_{u}$ and $w_{s 1}>w_{s 2}$. Labour market integration will create the possibility of migration of unskilled (skilled) workers from country 2 to country 1 in Case (i) (Case (ii)). We made these assumptions just for analytical simplicity, so that we can understand the effects of different types of migration clearly. In other words, for analytical simplicity, we separate out the effects of one type of wage difference when looking at the effects of another type of wage difference. It is needless to say that this simplification does not affect our qualitative results.

We consider the following game under no labour market integration and under labour market integration. At stage 1, the firms determine investments in innovation. At stage 2, they take their output decisions like Cournot duopolists and hire workers accordingly. We solve the game through backward induction.

\subsection{Integration creating the possibility of migration of unskilled workers}

We assume in this subsection the same wages for the skilled workers, i.e., $w_{s 1}=w_{s 2}=w_{s}$, but higher wages of the unskilled workers in country 1 under no integration, i.e., $w_{u 1}>w_{u 2}$.

\subsubsection{The output stage}

Firms 1 and 2 maximise the following expressions respectively to determine the outputs: 


$$
\operatorname{Max}_{q_{1}} \pi_{1}=\left(a-q_{1}-q_{2}-\lambda \alpha_{u} w_{u 1}\right) q_{1} \text { and } \operatorname{Max}_{q_{2}} \pi_{2}=\left(a-q_{1}-q_{2}-\beta w_{u 2}\right) q_{2}
$$

where $\lambda\left(R_{1}\right)=\theta_{1}-b_{1} R_{1}, \beta\left(R_{2}\right)=\theta_{2}-b_{2} R_{2}, \alpha_{u}=1$ under no labour market integration, and $\alpha_{u}=\frac{w_{u 2}}{w_{u 1}}$ under labour market integration.

The equilibrium outputs are

$$
\begin{aligned}
& q_{1}^{*}=\frac{a-2 \lambda \alpha_{u} w_{u 1}+\beta w_{u 2}}{3} \\
& q_{2}^{*}=\frac{a-2 \beta w_{u 2}+\lambda \alpha_{u} w_{u 1}}{3} .
\end{aligned}
$$

The outputs of both firms are positive for $a-2 \lambda \alpha_{u} w_{u 1}+\beta w_{u 2}>0$ and $a-2 \beta w_{u 2}+\lambda \alpha_{u} w_{u 1}>0$, which are assumed to hold.

The profits of firms 1 and firm 2 are respectively

$$
\begin{aligned}
& \pi_{1}^{*}=\frac{\left(a-2 \lambda \alpha_{u} w_{u 1}+\beta w_{u 2}\right)^{2}}{9} \\
& \pi_{2}^{*}=\frac{\left(a-2 \lambda w_{u 2}+\lambda \alpha_{u} w_{u 1}\right)^{2}}{9} .
\end{aligned}
$$

\subsection{The innovation stage}

Firms 1 and 2 maximise the following expressions to determine their investments in innovation:

$$
\begin{aligned}
& \Pi_{1}=\frac{\left(a-2 \lambda\left(R_{1}\right) \alpha_{u} w_{u 1}+\beta\left(R_{2}\right) w_{u 2}\right)^{2}}{9}-c_{1}\left(R_{1}\right) \\
& \Pi_{2}=\frac{\left(a-2 \beta\left(R_{2}\right) w_{u 2}+\lambda\left(R_{1}\right) \alpha_{u} w_{u 1}\right)^{2}}{9}-c_{2}\left(R_{2}\right),
\end{aligned}
$$

where $c_{1}\left(R_{1}\right)=c_{2}\left(R_{2}\right)=\frac{w_{s} R_{1}^{2}}{2}$ under both no integration and integration.

The equilibrium investments in innovation are given by the following expressions: 


$$
\begin{aligned}
& \frac{\partial \Pi_{1}}{\partial R_{1}}=-\frac{4}{9}\left(a-2 \lambda \alpha_{u} w_{u 1}+\beta w_{u 2}\right) \lambda^{\prime} \alpha_{u} w_{u 1}=c_{1}^{\prime} \\
& \frac{\partial \Pi_{2}}{\partial R_{2}}=-\frac{4}{9}\left(a-2 \beta w_{u 2}+\lambda \alpha_{u} w_{u 1}\right) \beta^{\prime} w_{u 2}=c_{2}^{\prime} .
\end{aligned}
$$

We assume that the second order conditions for maximisation are satisfied (See Appendix A for the calculation).

We determine the equilibrium investments in innovation by solving (9) and (10). The calculations for the equilibrium investments are given in Appendix A.

\subsection{The effects of labour market integration on innovation and consumer surplus}

To show the effects of labour market integration on the equilibrium investments in innovation, we first consider two special cases: (i) if only firm 1 innovates, and (ii) if only firm 2 innovates. It will then be easy to understand the effects of labour market integration under innovation by both firms, since this situation will be a combination of these special cases. However, as mentioned already, in no way, we visualise a situation where only the firm from a developing country, i.e., firm 2 , innovates. We consider this case just for the clarity of our analysis.

\subsubsection{Only firm 1 innovates}

If only the firm in the high-wage country, i.e., firm 1, innovates, the labour coefficients for firms 1 and 2 are respectively $\lambda_{1}$ and $\theta_{1}$.

Proposition 1: If only firm 1 (i.e., the firm in the high-wage country) innovates and labour market integration creates the possibility of migration of unskilled workers only, labour 
market integration decreases (increases) $R \& D$ investment compared to no integration if $a>(<) 2 \lambda\left(R_{1 n m}\right)\left(w_{u 1}+w_{u 2}\right)-\theta_{2} w_{u 2}$.

Proof: If only firm 1 innovates and labour market integration creates the possibility of migration of unskilled workers only, the equilibrium $R \& D$ investments of firm 1 under no integration and integration are respectively:

$$
\begin{aligned}
& -\frac{4}{9}\left(a-2 \lambda w_{u 1}+\theta_{2} w_{u 2}\right) \lambda^{\prime} w_{u 1}=w_{s} R_{1} \\
& -\frac{4}{9}\left(a-2 \lambda w_{u 2}+\theta_{2} w_{u 2}\right) \lambda^{\prime} w_{u 2}=w_{s} R_{1} .
\end{aligned}
$$

Denote the equilibrium R\&D investment of firm 1 under no labour market integration by $R_{1 n m}$. Evaluating left hand sides (LHSs) of (11) and (12) at $R_{1 n m}$, we get that LHS (11) > $<$ )

LHS (12) if $a>(<) 2 \lambda\left(R_{1 n m}\right)\left(w_{u 1}+w_{u 2}\right)-\theta_{2} w_{u 2}$, suggesting that labour market integration decreases (increases) firm 1's equilibrium R\&D investment compared to no integration.

Figure 1 is drawn to facilitate understanding of Proposition 1. The intersections of the marginal benefit and marginal cost curves determine the equilibrium investments in innovation ${ }^{5}$. We draw three marginal benefit curves. The middle one is under no integration. Under no integration, the marginal benefit is equal to marginal cost at $A$. The bottom one shows that integration shifts the marginal benefit curve downward, creating the new equilibrium at $B$, and reducing the equilibrium investment under integration. The top one shows that integration shifts the marginal benefit curve upward, creating the new equilibrium at $C$, and increasing the equilibrium investment under integration. However, if integration

\footnotetext{
${ }^{5}$ The expressions for marginal benefit from innovation are $\frac{4}{9} b_{1} w_{u 1}\left(a-2 \theta_{1} w_{u 1}+\theta_{2} w_{u 2}\right)+\frac{8}{9} b_{1}^{2} w_{u 1}{ }^{2} R_{1}$ under no integration, and $\frac{4}{9} b_{1} w_{u 2}\left(a-2 \theta_{1} w_{u 2}+\theta_{2} w_{u 2}\right)+\frac{8}{9} b_{1}{ }^{2} w_{u 2}{ }^{2} R_{1}$ under integration.
} 
shifts the marginal benefit curve upward, it is not certain that the equilibrium investment increases always, since the marginal benefit curve is now flatter and may intersect the marginal cost curve at a point where the investment is lower.

\section{Figure 1}

\section{Equilibrium R\&D with Unskilled Migration \\ (Only firm 1 innovates)}

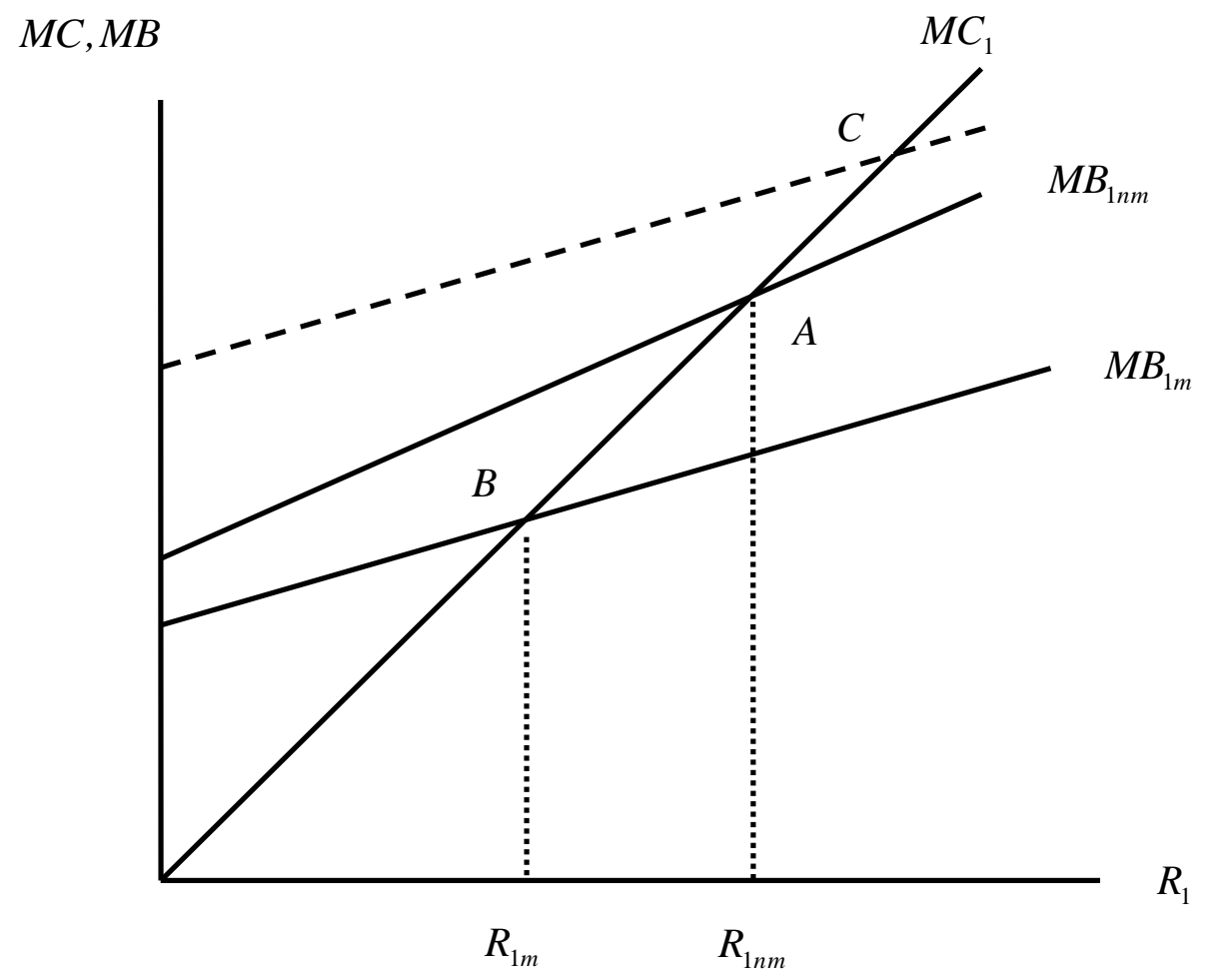

Intuitively, labour market integration creates two effects. On one hand, given the output of firm 1, a lower wage following integration reduces firm 1's marginal benefit from innovation by increasing its per-unit profit. This effect is positively related to the output of firm 1 , which is positively related to $a$. Hence, due to this effect, the higher the $a$ is, the lower is the incentive for innovation following integration. On the other hand, a lower wage increases the marginal benefit from innovation by increasing output and this effect is 
independent of $a$. The overall effect depends on the strengths of these forces. The higher is $a$, i.e., the higher is the market size, the higher is the chance that the former effect dominates the latter. If $a$ increases, LHS of the condition in Proposition 1 (i.e., $\left.a>(<) 2 \lambda\left(R_{1 n m}\right)\left(w_{u 1}+w_{u 2}\right)-\theta_{2} w_{u 2}\right)$ increases, while the right hand side (RHS) of that condition falls, since a higher $a$ increases $R_{1 n m}$ that reduces $\lambda\left(R_{1 n m}\right)$. Therefore, if only the firm in the high-wage country innovates, labour market integration reduces (increases) the equilibrium investment in innovation in large (small) markets. Thus, if the market size is large, an effect similar to Arrow's (1962) "replacement effect" is responsible for the innovation reducing effect of integration. On the other hand, if the market size is small, the effect of integration has a clear Schumpeterian overtone, where a cost reduction leads to increased innovation. The effects we observe here are similar to the effects of outsourcing on the investment in innovation in Marjit and Mukherjee (2008).

The policy implication of this result is quite significant. There exists a notion in the policy literature that the availability of cheap labour may delay development and adoption of technological solutions and a labour shortage can encourage innovation (International Organization of Migration 2010, page 323; Migration Advisory Committee 2013, page 174) . The above result to some extent supports that view.

Since labour market integration affects investments in innovation and the marginal costs of production, the effects of integration on consumers are not immediate. Labour market integration increases consumer surplus if it increases the total output compared to no integration and it happens if the total marginal costs of the firms are lower under integration compared to no integration. By comparing the total outputs under integration and no integration, we obtain that labour market integration, creating the possibility of migration of unskilled workers, increases (decreases) consumers' welfare if $\lambda\left(R_{1 m}\right) w_{u 2}<(>) \lambda\left(R_{1 n m}\right) w_{u 1}$. Since firm 2's marginal cost remains unaffected under labour market integration, the 
comparison depends on firm 1's marginal costs. Although integration reduces the wage in country 1 from $w_{u 1}$ to $w_{u 2}$, it increases the labour coefficient if the market is sufficiently large, as shown in Proposition 1. Hence, the marginal cost of firm 1 can be higher under integration if integration creates significant adverse effect on innovation, i.e., $\lambda\left(R_{1 m}\right)$ is sufficiently higher compared to $\lambda\left(R_{1 n m}\right)$, so that the adverse technology effect dominates the beneficial wage effect.

The following proposition is immediate from the above discussion.

Proposition 2: If only firm 1 (i.e., the firm in the high-wage country) innovates and labour market integration creates the possibility of migration of unskilled workers only, labour market integration may make the consumers worse off compared to no integration if the market is sufficiently large so that $a>2 \lambda\left(R_{1 n m}\right)\left(w_{u 1}+w_{u 2}\right)-\theta_{2} w_{u 2}$.

\subsubsection{Only firm 2 innovates}

Proposition 3: If only firm 2 (i.e., the firm in the low-wage country) innovates and labour market integration creates the possibility of migration of unskilled workers only, labour market integration reduces the $R \& D$ investment of firm 2, but it hurts (benefits) the consumers if $\lambda<(>) \frac{w_{u 2}\left[\beta\left(R_{2 m}\right)-\beta\left(R_{2 n m}\right)\right]}{\left(w_{u 1}-w_{u 2}\right)}$.

Proof: If only firm 2 innovates and labour market integration creates the possibility of migration of unskilled workers only, the equilibrium R\&D investments of firm 2 under no integration and integration are respectively:

$$
-\frac{4}{9}\left(a-2 \beta w_{u 2}+\theta_{1} w_{u 1}\right) \beta^{\prime} w_{u 2}=c_{2}^{\prime}
$$




$$
-\frac{4}{9}\left(a-2 \beta w_{u 2}+\theta_{1} w_{u 2}\right) \beta^{\prime} w_{u 2}=c_{2}^{\prime}
$$

Denote the equilibrium R\&D investment of firm 2 under no labour market integration by $R_{2 n m}$. Evaluating LHSs of (13) and (14) at $R_{2 n m}$, we get that LHS of (13) > LHS of (14), suggesting that the labour market integration reduces the R\&D investment of firm 2 .

In order to compare consumers' welfare under no integration to that of under integration, we need to compare the respective equilibrium outputs. The total outputs under no integration and under integration are respectively $Q_{n m}=\frac{1}{3}\left[2 a-\lambda w_{u 1}-\beta\left(R_{2 n m}\right) w_{u 2}\right]$ and $Q_{m}=\frac{1}{3}\left[2 a-\lambda w_{u 2}-\beta\left(R_{2 m}\right) w_{u 2}\right]$. We get that $Q_{n m}>(<) Q_{m}$ for $\lambda<(>) \frac{w_{u 2}\left[\beta\left(R_{2 m}\right)-\beta\left(R_{2 n m}\right)\right]}{\left(w_{u 1}-w_{u 2}\right)}$, suggesting that consumers' welfare are higher (lower) under no integration if $\lambda<(>) \frac{w_{u 2}\left[\beta\left(R_{2 m}\right)-\beta\left(R_{2 n m}\right)\right]}{\left(w_{u 1}-w_{u 2}\right)}$.

The intuitions for the above results are as follows. Given the R\&D investment of firm 2, labour market integration increases firm 1's output and reduces firm 2's output and profit, which, in turn, reduces firm 2's investment in R\&D.

Given the R\&D investment of firm 2, labour market integration creates cost efficiency in the industry by allowing migration of unskilled workers, which helps to increase the total output. However, since integration reduces the R\&D investment of firm 2 , it tends to reduce the total output. If integration reduces firm 2's R\&D investment significantly so that $\lambda\left(w_{u 1}-w_{u 2}\right)<w_{u 2}\left[\beta\left(R_{2 m}\right)-\beta\left(R_{2 n m}\right)\right]$, integration reduces the total output and makes the consumers worse off. Otherwise, integration increases the total output and makes the consumers better off. 


\subsubsection{Innovation by both firms}

Now it must be clear that if both firms innovate, the effects of labour market integration will be the combinations of the effects shown in subsections 3.3.1 and 3.3.2.1. We discuss the implications of innovation by both firms briefly in this section. The calculations of the reaction functions and the equilibrium investments in innovation by firms 1 and 2 are given in Appendix B. Since the effects of integration on the equilibrium investments in innovation are cumbersome and clear cut results are difficult to obtain, we will plot the reaction functions in Figure 2 to evaluate the effects of integration.

In Figure 2, the solid line 1 shows firm 1's reaction function under no integration. The reaction function under integration derived in Appendix $B$ shows that the intercept in $R_{1}$ axis under integration may either increase or decrease, depending on the parameter values. In Figure 2, we draw the broken line 1 and the dotted line 3 to show firm 1's reaction functions under integration when the intercept decreases and when the intercept increases respectively. It follows from Appendix $B$ that, under integration, the intercept of firm 1's reaction function in $R_{2}$ axis increases and the slope decreases.

We have also plotted the reaction functions of firm 2 in Figure 2 by denoting them as line 2. The solid line 2 is the reaction function under no integration and the broken line 2 is the reaction function under integration. Integration increases the reaction function's intercept in $R_{1}$ axis and makes the slope of the reaction function steeper. The reaction function's intercept in the $R_{2}$ axis however falls after integration as can be observed from equation (A2) in Appendix $A$ assuming $R_{1}=0$. 


\section{Figure 2 \\ Equilibrium R\&D with Unskilled Migration \\ (Both firms innovate)}

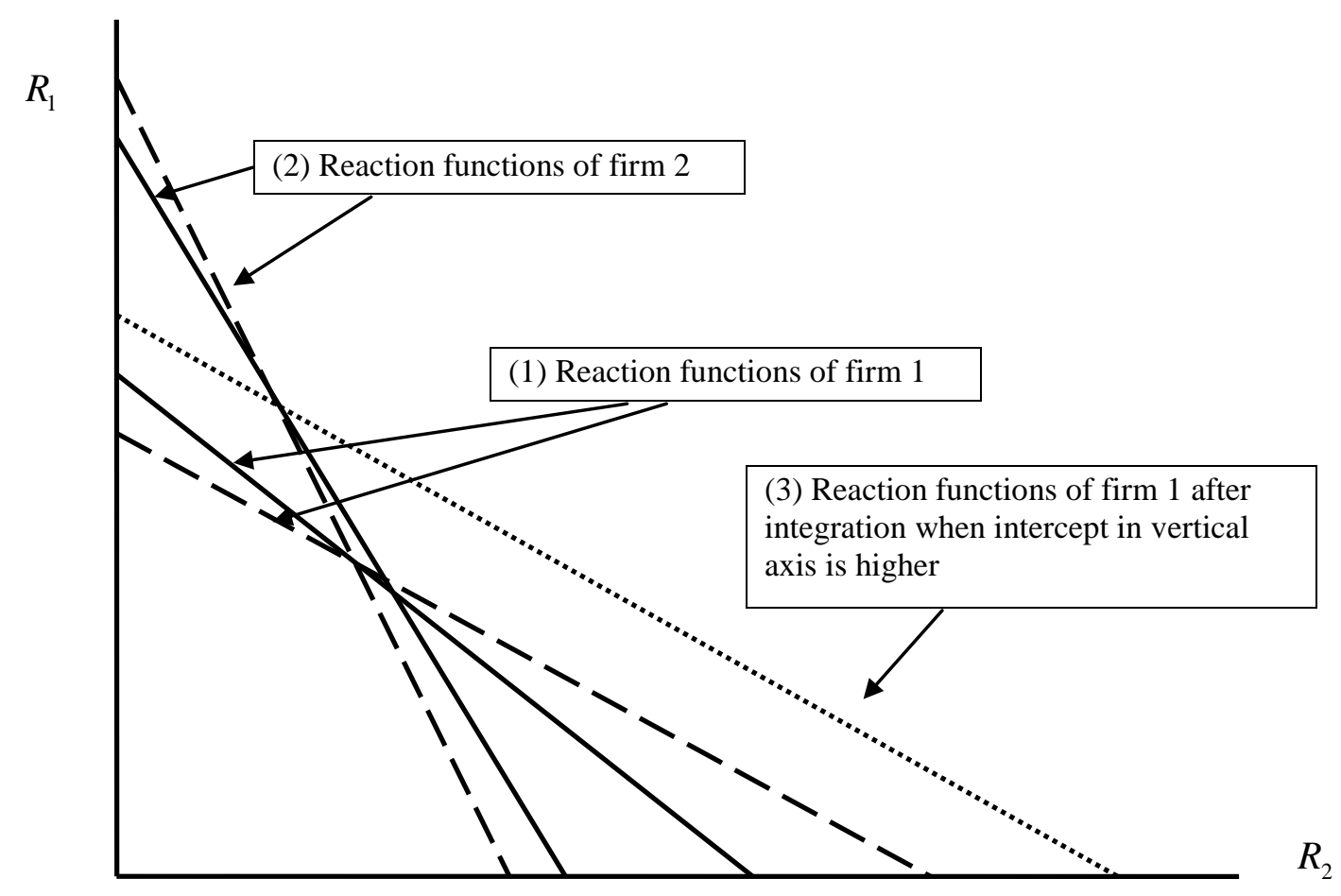

Proposition 1 shows that when firm 2 does not innovate, integration decreases (increases) firm 1's investment in innovation if the market size is large (small). However, Proposition 3 shows that when firm 1 does not innovate, integration decreases firm 2's investment in innovation. Hence, Propositions 1 and 3 show the effects of integration on the firms' stand alone incentives for R\&D investment. However, if both firms innovate, there is also a strategic incentive for $R \& D$ investment. Since the reaction functions for the $R \& D$ investments are downward sloping, as shown in Figure 2, higher R\&D investment of one firm decreases the R\&D investment of the other firm. Hence, it is immediate that if the market size is small, integration increases $R \& D$ investment of firm 1 and decreases the $R \& D$ investment of firm 2. However, if the market size is large, firm 1's lower stand alone incentive for innovation after integration increases firm 2's strategic incentive for innovation and viceversa. In this situation, whether integration decreases or increases the firms' $R \& D$ 
investments is ambiguous and depends on the relative strengths of the stand alone incentive and the strategic incentive, which depend on the parameter values. The reaction functions 1 and 2 show the situation where integration increases the R\&D investment of firm 1 and reduces the $R \& D$ investment firm 2 .

It must also be clear that if both firms innovate, the effects of integration on the consumers will be a combination of effects shown in Propositions 2 and 3, suggesting that consumers may be better off or worse off after integration compared to no integration depending on the parameter values.

\section{Integration creating migration of skilled workers only}

The above section has considered that wages of the unskilled workers are different under no labour market integration, and labour market integration creates the possibility of migration of unskilled workers. This section considers the other case where wages of the unskilled workers are the same but wages of the skilled workers are different under no integration, i.e., $w_{u 1}=w_{u 2}=w_{u}$ and $w_{s 1}>w_{s 2}$ Hence, labour market integration creates the possibility of migration of skilled workers to country 1 .

It is trivial that integration of labour markets in this section does not create the possibility of migration of skilled workers if firm 1 does not innovate, since skilled workers are used for innovation. Hence, we consider innovation by only firm 1 and innovation by both firms in this section.

If wages of the unskilled workers are the same under no labour market integration and under labour market integration, firms 1 and 2 maximise the following expressions respectively to determine the outputs:

$$
\operatorname{Max}_{q_{1}} \pi_{1}=\left(a-q_{1}-q_{2}-\lambda w_{u}\right) q_{1} \text { and } \operatorname{Max}_{q_{2}} \pi_{2}=\left(a-q_{1}-q_{2}-\beta w_{u}\right) q_{2}
$$


The equilibrium outputs are $q_{1}{ }^{*}=\frac{a-2 \lambda w_{u}+\beta w_{u}}{3}$ and $q_{2}{ }^{*}=\frac{a-2 \beta w_{u}+\lambda w_{u}}{3}$. The outputs of both firms are positive for $a-2 \lambda w_{u}+\beta w_{u}>0$ and $a-2 \beta w_{u}+\lambda w_{u}>0$, which are assumed to hold.

The profits of firms 1 and firm 2 are respectively $\pi_{1}^{*}=\frac{\left(a-2 \lambda w_{u}+\beta w_{u}\right)^{2}}{9}$ and $\pi_{2}^{*}=\frac{\left(a-2 \lambda w_{u}+\lambda w_{u}\right)^{2}}{9}$

\subsection{Innovation by firm 1 only}

If only firm 1 innovates and labour market integration creates the possibility of migration of only skilled workers, firm 1 maximises the following expression to determine the R\&D investment:

$$
\Pi_{1}=\frac{\left[a-2\left(\theta_{1}-b_{1} R_{1}\right) w_{u}+\theta_{2} w_{u}\right]^{2}}{9}-\frac{\alpha_{s} w_{s 1} R_{1}^{2}}{2},
$$

where $\alpha_{s}=1$ under no integration and $\alpha_{s}=\frac{w_{s 2}}{w_{s 1}}$ under integration. The equilibrium $\mathrm{R} \& \mathrm{D}$ investment is $R_{1}=\frac{4\left(b_{1} a w_{u}-2 b_{1} \theta_{1} w_{u}{ }^{2}+b_{1} \theta_{2} w_{u}{ }^{2}\right)}{9 \alpha_{s} w_{s 1}-8 b_{1}{ }^{2} w_{u}{ }^{2}}$. The possibility of migration of only skilled workers following labour market integration reduces $9 \alpha_{s} w_{s 1}-8 b_{1}{ }^{2} w_{u}{ }^{2}(>0)$ and increases the R\&D investment.

Since integration increases $R \& D$ investment while keeping wages of the unskilled workers unchanged, it makes the consumers better off by increasing the total output.

The following proposition is immediate from the above discussion. 
Proposition 4: If only firm 1 innovates and labour market integration creates the possibility of migration of skilled workers only, labour market integration increases $R \& D$ investment and consumers' welfare compared to no migration.

The reason for the above result is as follows. The cost of doing $R \& D$ falls with integration and increases firm 1's R\&D investment, which increases the equilibrium output and welfare.

Figure 3 shows what happens if the labour market integration creates the possibility of migration of skilled workers only. Migration of skilled people does not change the slope and intercept of the marginal benefit line as production requires unskilled workers. However, it reduces the marginal cost of undertaking innovation. As the marginal cost of undertaking innovation is always zero with no $\mathrm{R} \& \mathrm{D}$, the marginal cost lines start from the origin. The marginal cost curve pivot down from the origin after integration. Hence, the equilibrium R\&D investments under no integration and under integration occur at $A$ and $B$ respectively, suggesting that integration increases the $R \& D$ investment. 


\section{Figure 3 \\ Equilibrium R\&D with Skilled Migration \\ (Only firm 1 innovates)}

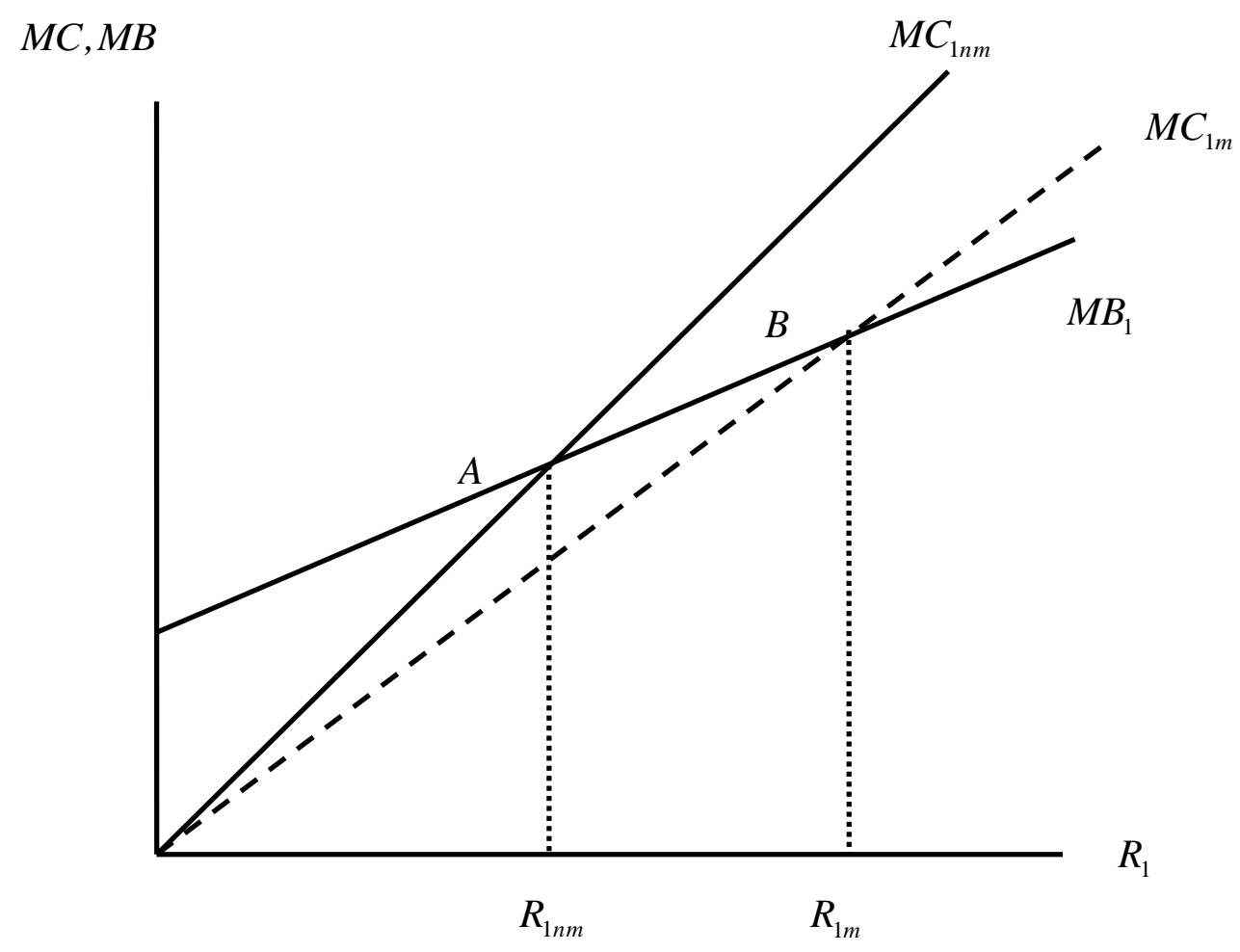

The above result points towards a beneficial effect of Brain Drain. Given the limitation of the developing countries in performing research, migration of the skilled people to the developed countries helps to create better technologies in the developed-country firms ${ }^{6}$, and it benefits the developed as well as the developing countries. The result somehow echoes that of Grubel and Scott (1966) on international flow of human capital. They mentioned that the largest benefit of people migrating abroad can come through the pure research of scientists and engineers. If the work condition in the new country is better, the productivity is high and the native country gains more from scientists emigrating abroad.

\footnotetext{
${ }^{6}$ For example, Rashidi and Pyka (2013) noted that about $50 \%$ of engineers and scientist employed in Silicon Valley are immigrants.
} 


\subsection{If both firms innovate}

If both firms innovate, firms 1 and 2 maximise the following expressions to determine their investments in R\&D:

$$
\begin{aligned}
& \Pi_{1}=\frac{\left(a-2 \lambda\left(R_{1}\right) w_{u}+\beta\left(R_{2}\right) w_{u}\right)^{2}}{9}-\frac{\alpha_{s} w_{s 1} R_{1}^{2}}{2} \\
& \Pi_{2}=\frac{\left(a-2 \beta\left(R_{2}\right) w_{u}+\lambda\left(R_{1}\right) w_{u}\right)^{2}}{9}-\frac{w_{s 2} R_{2}{ }^{2}}{2}
\end{aligned}
$$

where $\alpha_{s}=1$ under no integration and $\alpha_{s}=\frac{w_{s 2}}{w_{s 1}}$ under integration.

Proposition 5: If both firms innovate and labour market integration creates the possibility of migration of skilled workers only, integration increases the $R \& D$ investment of firm 1 and decreases the $R \& D$ investment of firm 2.

Proof: The equilibrium R\&D of firm 1 is derived in Appendix $A$. As $w_{s 1}>w_{s 2}$, the denominator decreases with migration (see Appendix $C$ ). Hence, the equilibrium $\mathrm{R} \& \mathrm{D}$ investment of firm 1 increases with migration.

Now consider the effects of labour market integration of the equilibrium R\&D investment of firm 2. If the marginal benefits are evaluated at no migration equilibrium $R \& D$, we get that $M B_{2 n m}>M B_{2 m}$. In addition, by looking at the reaction function of firm 2 in equation (A2) of Appendix A, we see that firm 2 reduces the R\&D investment for higher equilibrium R\&D investment of firm 1 . Therefore, $R \& D$ investment of firm 2 falls with the migration of skilled workers.

Firm 1 can now conduct R\&D relatively cheaply under labour market integration. Hence, labour market integration increases firm 1's marginal benefit from innovation 
compared to no labour market integration, thus increasing firm 1's R\&D investment under integration compared to no integration. On the other hand, labour market integration reduces firm 2's marginal benefit from innovation and reduces its R\&D investment.

To look at the matter further, we plot the reaction functions of two firms in Figure 4. For simplicity, we assume in the figure that $b_{1}=b_{2}=b, \theta_{1}=\theta_{2}=\theta$ and $w_{u 1}=w_{u 2}=w_{u}$. Therefore, equations (A1) and (A2) in Appendix $A$ are $R_{1}=\frac{4 b a w_{u}-8 b \theta w_{u}{ }^{2}+4 b \theta w_{u} w_{u}}{9 \alpha_{s} w_{s 1}-8 b^{2} w_{u}{ }^{2}}-\frac{4 b b w_{u} w_{u}}{9 \alpha_{s} w_{s 1}-8 b^{2} w_{u}{ }^{2}} R_{2} \quad$ and $R_{2}=\frac{4 b a w_{u}-8 b \theta w_{u}{ }^{2}+4 b \theta w_{u} w_{u}}{9 w_{s 2}-8 b^{2} w_{u}{ }^{2}}-\frac{4 b b w_{u} w_{u}}{9 w_{s 2}-8 b^{2} w_{u}{ }^{2}} R_{1}$ respectively.

In Figure 4, we have indicated the reaction function of firm 1 by the flatter lines denoted by (1). The flatter broken line indicates the reaction function of firm 1 under integration. The steeper line denoted by (2) is the reaction function of firm 2. Under integration, both firms experience the same wage, $w_{s 2}$, for skilled workers. Given all other things same, the equilibrium $R \& D$ investments are the same under integration and they are indicated by point $B$, where the solid steeper line and the flatter broken line have crossed.

Now we want to see the equilibrium R\&D investment under no integration, i.e., if firm 1 faces the wage $w_{s 1}$. We can see from the equations that the reaction function of firm 2 remains unchanged. However, firm 1 has a different reaction function under no integration. Since $w_{s 1}>w_{s 2}$ under no integration, the vertical intercept of firm 1's reaction function decreases. The denominator of the slope term is also higher for firm 1 as $w_{s 1}>w_{s 2}$. Hence, the absolute slope of firm 1's reaction function falls. Looking further at the equation, it can be seen that the horizontal intercept of firm 1's reaction function remains unchanged. Therefore, firm 1's reaction function is flatter under no integration and it is given by the solid line (1). The equilibrium $\mathrm{R} \& \mathrm{D}$ investments under no integration are indicated by point $A$. Hence, 
labour market integration increases firm 1's $R \& D$ investment and reduces firm 2's R\&D investment.

\section{Figure 4 \\ Equilibrium R\&D with Skilled Migration \\ (Both firms innovate)}

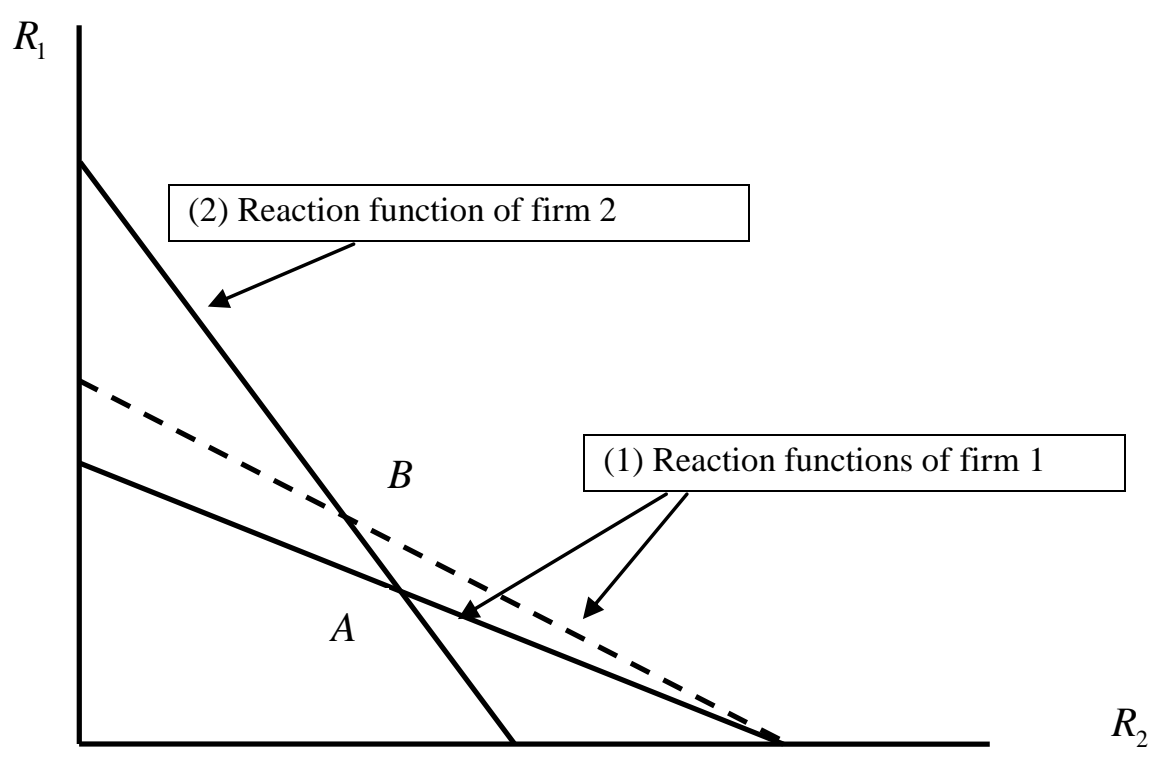

The effect of labour market integration on the consumers is not immediate as integration increases firm 1's R\&D investment but it reduces firm 2's R\&D investment. The consumer surplus is higher under integration if $Q_{m}=\frac{2 a-\lambda_{m} w_{u}-\beta_{m} w_{u}}{3}$ is greater than $Q_{n m}=\frac{2 a-\lambda_{n m} w_{u}-\beta_{n m} w_{u}}{3}$ or $R_{1 m}-R_{1 n m}>R_{2 n m}-R_{2 m}$, i.e., the increase in firm 1's R\&D investment is higher than the reduction in firm 2's R\&D investment. Since integration does not affect firm 2's reaction function, the change in the equilibrium R\&D investments can be found through a movement along firm 2's reaction function. We get that $\left|\frac{\partial R_{2}}{\partial R_{1}}\right|=\frac{4 b_{1} b_{2} w_{u} w_{u}}{9 w_{s 2}-8 b_{1}^{2} w_{u}{ }^{2}}<1 \quad, \quad$ since the stability of the equilibrium requires 
$4 b_{1} b_{2} w_{u} w_{u}<9 w_{s 2}-8 b_{1}{ }^{2} w_{u}{ }^{2}$, implying that the change in firm 1's R\&D investment is more than the change in firm 2's R\&D investment. Hence, labour market integration increases consumer surplus compared to no labour market integration.

The following result is immediate from the above discussion.

Proposition 6: If both firms innovate and labour market integration creates the possibility of migration of skilled workers only, integration makes the consumers better off.

The reason for the above result is as follows. Labour market integration reduces the skilled-wage and creates a stronger positive direct effect on firm 1's R\&D investment relative to the negative indirect effect on firm 2's R\&D investment. Thus, labour market integration increases consumer surplus.

\section{Discussions}

\subsection{When the labour supply is not perfectly elastic}

The constant wages assumed in our analysis has helped to show our results in the simplest way. Moreover, as mentioned already, if the number of workers employed in the industry under question is sufficiently small compared to the number of workers available in the economy, a constant wage faced by the concerned industry may not be a reasonable assumption. However, our qualitative results would hold if the labour supplies are not perfectly elastic.

If the labour supply curves are not perfectly elastic, migration will tend to increase wage in the source country and it would tend to decrease wage in the recipient country. Hence, unlike our analysis, wage under migration would not be equal to the initial low-wage. Rather, it would be somewhere between the initial high-wage and the low-wage. Hence, 
following migration, output expansion in the recipient country's firm and output contraction in the source country's firm would be less compared to our analysis. As a result, on one hand, the effect on the marginal benefit from innovation due to a change in the wage would be lower, and on the other hand, the effect on the marginal benefit from innovation due to a change in the output would also be lower. Hence, if the labour supplies are not perfectly elastic, whether the effects of migration will tend to increase or decrease innovation compared to our case, where the labour supplies are perfectly elastic, would depend on these two effects, which, in turn, would depend on the elasticities of labour supply and labour demand.

\subsection{The effects of entry}

The analysis of Section 3 shows that labour market integration creates a trade-off between low wage and low R\&D investment and may make the consumers worse off following labour market integration. We have derived those results under a given market structure, thus ignoring the implications of market entry in the recipient country following labour market integration. However, lower wage in the recipient country following labour market integration may encourage entry of new firms, thus creating further impacts. Now we discuss briefly the implications of entry of new firms. ${ }^{7}$

Entry of new firms creates two opposite effects on the incentive for innovation. First, as competition increases, for a given $R \& D$ investment, entry of new firms reduces the innovating firm's market share and profit, thus decreasing the incentive for R\&D investment. This effect has a clear Schumpeterian overtone, where lower profit generation reduces the incentive for innovation. On the other hand, since innovation helps the innovating firm to steal business from its competitors by reducing the innovator's marginal cost, higher

\footnotetext{
${ }^{7}$ We thank an anonymous referee for encouraging us to discuss this issue.
} 
competition in the market following entry may encourage the innovator to invest more in R\&D to secure a higher market share. This effect is similar to Arrow's (1962) "replacement effect" that increases the incentive for innovation under higher competition. Hence, the effect of entry on innovation may be non-monotonic, and whether entry of new firms will increase or decrease the incentive for innovation will therefore depend on the market-share effect, which tends to reduce R\&D investment, and on the business stealing effect, which tends to increase $\mathrm{R} \& \mathrm{D}$ investment. ${ }^{8}$

The above argument implies that if labour market integration encourages entry of new firms by reducing wage, whether it increases or decreases the possible trade-off on consumer surplus by reducing both wage and R\&D investment is not immediate and depends on the above-mentioned market-share effect and the business stealing effect. In this respect, whether the entrants are innovators or non-innovators may also play an important role. These issues deserve a separate full-fledged analysis and we leave them for future research.

\section{Conclusions}

We analyse the effects of labour market integration on consumers' welfare, highlighting its effect on innovation. Labour market integration creates the possibility of migration of skilled and unskilled workers. Skilled workers used for innovation and unskilled workers are used for production. We show that if labour market integration creates the possibility of migration of skilled workers, it increases investments in innovation and benefits the consumers. However, if labour market integration creates the possibility of migration of unskilled workers, the effects on both innovation and consumers are ambiguous. Our results suggest that the effects of labour market integration on the consumers depend on several factors such

\footnotetext{
${ }^{8}$ In an earlier work, Dasgupta and Stiglitz (1980) show the relation between product-market concentration and the $R \& D$ intensity. The relation between the number of firms and $R \& D$ investment also follows from a more recent work of Mattoo et al. (2004). However, those papers ignore the issue of labour immigration, which is the focus of our paper.
} 
as the market size, labour coefficients, wage and the type of migrated workers (i.e., skilled or unskilled workers).

This paper is supporting to some extent the recent literature showing the beneficial effects of international labour migration. The literature claims that benefit of international migration can occur through increased human capital formation. This paper points to another channel, viz., through $R \& D$ investment. If the $R \& D$ investments are higher, production of output can be higher and consequently price can be lower. As we have seen, labour market integration may increase the total output by increasing the R\&D investments. Labour market integration always increases the $R \& D$ investment when it creates the possibility of migration of skilled workers. However, the possibility of migration of unskilled workers under integration may create negative effects on the R\&D investments, yet may increase the total output.

It is important to note that many countries may not have resources to conduct innovation, although they may create professionals, such as computer engineers, aeronautical engineers, marine engineers, pharmaceutical and chemical engineers, for conducting innovation. Recent Brain Drain literature claims that international migration is beneficial as it gives incentive to acquire these skills. For example, it is possible for many countries to train pharmacists and chemists relatively cheaply, but they may not have large pharmaceutical sectors. Hence, knowledge created in those countries may not be useful unless that is used in other places.

We show in this paper that migration of skilled people may bring benefit through higher R\&D. When labour markets are integrated, skilled workers can migrate and contribute by innovating better technologies, and the benefit of better technologies flow to both the source and the recipient countries. However, as shown, the effects of migration of unskilled workers are not so straightforward. 
Our paper is a first step to show the effects of labour market integration on consumers through its effect on innovation. A natural way to analyse this problem is to consider a partial equilibrium analysis focusing on a particular industry. While a partial equilibrium analysis helps us to show the strategic effects easily, it ignores income effects. An extension of our paper will be to consider a general equilibrium approach with innovation, thus incorporating both the strategic effects and the income effects of labour market integration. In this respect, other issues such as unemployment in the economy, affecting the income effects, may also worth considering. We leave these issues for future research. 


\section{Appendix}

A: $\quad$ From equation (9), we get the reaction function of firm 1 as:

$$
R_{1}=\frac{4 b_{1} a \alpha_{u} w_{u 1}-8 b_{1} \theta_{1} \alpha_{u}{ }^{2} w_{u 1}{ }^{2}+4 b_{1} \theta_{2} w_{u 2} \alpha_{u} w_{u 1}}{9 w_{s}-8 b_{1}{ }^{2} \alpha_{u}{ }^{2} w_{u 1}{ }^{2}}-\frac{4 b_{1} b_{2} w_{u 2} \alpha_{u} w_{u 1}}{9 w_{s}-8 b_{1}{ }^{2} \alpha_{u}{ }^{2} w_{u 1}{ }^{2}} R_{2}
$$

We assume that $\left(a-2 \theta_{1} \alpha_{u 1} w_{u 1}+\theta_{2} w_{u 2}\right)>0$, so that the outputs and the profits are positive.

Therefore, $4 b_{1} a \alpha_{u} w_{u 1}-8 b_{1} \theta_{1} \alpha_{u}{ }^{2} w_{u 1}{ }^{2}+4 b_{1} \theta_{2} w_{u 2} \alpha_{u} w_{u 1}$ is positive. We also assume that $9 w_{s}-8 b_{1}^{2} \alpha_{u}{ }^{2} w_{u 1}{ }^{2}>0$ to ensure $R_{1}>0$ when $R_{2}=0$. The own second partial and the cross second partial derivatives are $\frac{\partial^{2} \Pi_{1}}{\partial R_{1}{ }^{2}}=\frac{1}{9}\left(8 b_{1}{ }^{2} \alpha_{u}{ }^{2} w_{u 1}{ }^{2}-9 w_{s}\right)$ and $\frac{\partial^{2} \Pi_{1}}{\partial R_{1} \partial R_{2}}=-\frac{4}{9} b_{1} b_{2} \alpha_{u} w_{u 1} w_{u 2}$.

Both the derivatives are negative by assumption.

From equation (10), the reaction function of firm 2 is obtained as:

$$
R_{2}=\frac{4 b_{2} a w_{u 2}-8 b_{2} \theta_{2} w_{u 2}{ }^{2}+4 b_{2} \theta_{1} \alpha_{u} w_{u 1} w_{u 2}}{9 w_{s}-8 b_{2}{ }^{2} w_{u 2}{ }^{2}}-\frac{4 b_{1} b_{2} \alpha_{u} w_{u 1} w_{u 2}}{9 w_{s}-8 b_{2}{ }^{2} w_{u 2}{ }^{2}} R_{1}
$$

Again, $4 b_{2} a w_{u 2}-8 b_{2} \theta_{2} w_{u 2}{ }^{2}+4 b_{2} \theta_{1} \alpha_{u} w_{u 1} w_{u 2}$ is negative as required for the positive output and profit. In addition, we assume that $9 w_{s}-8 b_{2}{ }^{2} w_{u 2}{ }^{2}>0$ to ensure that $R_{2}>0$ when $R_{1}=0$. Hence, the own second partial and cross second partial derivatives are $\frac{\partial^{2} \Pi_{2}}{\partial R_{2}{ }^{2}}=\frac{1}{9}\left(8 b_{2}{ }^{2} w_{u 2}{ }^{2}-9 w_{s}\right) \quad$ and $\quad \frac{\partial^{2} \Pi_{2}}{\partial R_{2} \partial R_{1}}=-\frac{4}{9} b_{1} b_{2} \alpha_{u} w_{u 1} w_{u 2} \quad . \quad$ Stability requires that $\left|\frac{\partial^{2} \Pi_{2}}{\partial R_{2}^{2}}\right|>\left|\frac{\partial^{2} \Pi_{2}}{\partial R_{2} \partial R_{1}}\right|$

The equilibrium values of $R_{1}$ and $R_{2}$, obtained from equations (A1) and (A2) using the Cramer's rule, are

$$
R_{1}^{*}=\phi^{-1}\left(\begin{array}{l}
-48 b_{1} a \alpha_{u} w_{u 1} b_{2}{ }^{2} w_{u 2}{ }^{2}+48 b_{1} \theta_{1} \alpha_{u}{ }^{2} w_{u 1}{ }^{2} b_{2}{ }^{2} w_{u 2}{ }^{2} \\
+36 b_{1} a \alpha_{u} w_{u 1} w_{s}-72 b_{1} \theta_{1} \alpha_{u}{ }^{2} w_{u 1}{ }^{2} w_{s}+36 b_{1} \theta_{2} w_{u 2} \alpha_{u} w_{u 1} w_{s}
\end{array}\right)
$$




$$
R_{2}^{*}=\phi^{-1}\left(\begin{array}{l}
-48 b_{2} a w_{u 2} b_{1}^{2} \alpha_{u}^{2} w_{u 1}{ }^{2}+48 b_{2} \theta_{2} w_{u 2}{ }^{2} b_{1}^{2} \alpha_{u}{ }^{2} w_{u 1}{ }^{2} \\
+36 b_{2} a w_{u 2} w_{s}-72 b_{2} \theta_{2} w_{u 2}{ }^{2} w_{s}+36 b_{2} \theta_{1} \alpha_{u} w_{u 1} w_{u 2} w_{s}
\end{array}\right)
$$

where $\phi=48 b_{1}{ }^{2} b_{2}{ }^{2} \alpha_{u}{ }^{2} w_{u 1}{ }^{2} w_{u 2}{ }^{2}-72 b_{2}{ }^{2} w_{u 2}{ }^{2} w_{s}-72 b_{1}{ }^{2} \alpha_{u}{ }^{2} w_{u 1}{ }^{2} w_{s}+81 \alpha_{s} w_{s}{ }^{2}$ and $\phi^{-1}$ is the inverse of $\phi$. We assume that the denominator is positive so that the solutions are positive and stable.

\section{B: $\quad$ Reaction functions of firm 1 in section 3.4:}

Under no integration, $R_{1}=\frac{4 b_{1} a w_{u 1}-8 b_{1} \theta_{1} w_{u 1}{ }^{2}+4 b_{1} \theta_{2} w_{u 2} w_{u 1}}{9 w_{s}-8 b_{1}^{2} w_{u 1}^{2}}-\frac{4 b_{1} b_{2} w_{u 1} w_{u 2}}{9 w_{s}-8 b_{1}^{2} w_{u 1}{ }^{2}} R_{2}$.

Under integration, $R_{1}=\frac{4 b_{1} a w_{u 2}-8 b_{1} \theta_{1} w_{u 2}^{2}+4 b_{1} \theta_{2} w_{u 2} w_{u 2}}{9 w_{s}-8 b_{1}^{2} w_{u 2}^{2}}-\frac{4 b_{1} b_{2} w_{u 2} w_{u 2}}{9 w_{s}-8 b_{1}^{2} w_{u 2}{ }^{2}} R_{2}$.

\section{The intercept in horizontal axis:}

When $R_{1}=0, \quad R_{2}=\frac{4 b_{1} a w_{u 1}-8 b_{1} \theta_{1} w_{u 1}{ }^{2}+4 b_{1} \theta_{2} w_{u 2} w_{u 1}}{4 b_{1} b_{2} w_{u 1} w_{u 2}}=\frac{4 b_{1} a-8 b_{1} \theta_{1} w_{u 1}+4 b_{1} \theta_{2} w_{u 2}}{4 b_{1} b_{2} w_{u 2}}$ under no integration, and $R_{2}=\frac{4 b_{1} a-8 b_{1} \theta_{1} w_{u 2}+4 b_{1} \theta_{2} w_{u 2}}{4 b_{1} b_{2} w_{u 2}}$ under integration.

\section{Changes in the slope:}

Migration in our case reduces the value of $\alpha_{u}$. To find out the effect of a change in $\alpha_{u}$ on the slope, we can differentiate the slope term of the reaction function by $\alpha_{u}$. Let $S$ be the slope. Therefore,

$$
\frac{\partial S}{\partial \alpha_{u}}=-\left(\frac{4 b_{1} b_{2} \alpha_{u} w_{u 1} w_{u 2}}{\left(9 w_{s}-8 b_{1}{ }^{2} \alpha_{u}{ }^{2} w_{u 1}{ }^{2}\right)^{2}} 16 b_{1}{ }^{2} \alpha_{u} w_{u 1}{ }^{2}+\frac{4 b_{1} b_{2} w_{u 1} w_{u 2}}{\left(9 w_{s}-8 b_{1}{ }^{2} \alpha_{u}{ }^{2} w_{u 1}{ }^{2}\right.}\right)
$$

As $9 w_{s}-8 b_{1}{ }^{2} \alpha_{u}{ }^{2} w_{u 1}{ }^{2}$ is positive by assumption, the slope moves to the opposite direction of the change of $\alpha_{u}$. The slope is negative. Hence the slope is steeper if $\alpha_{u}$ increases. If $\alpha_{u}$ falls, 
the slope is flatter. Therefore, under integration, as $\alpha_{u}$ falls, we get a relatively flatter reaction function.

\section{Reaction functions of firm 2 in section 3.4:}

Using equation (A2), we get that $R_{1}=\frac{4 a-8 \theta_{2} w_{u 2}}{4 b_{1} w_{u 1}}+\frac{4 \theta_{1}}{4 b_{1}}-\frac{\left(9 w_{s}-8 b_{2}{ }^{2} w_{u 2}{ }^{2}\right)}{4 b_{1} b_{2} w_{u 1} w_{u 2}} R_{2}$ if there is no integration, and $R_{1}=\frac{4 a-8 \theta_{2} w_{u 2}}{4 b_{1} w_{u 2}}+\frac{4 \theta_{1}}{4 b_{1}}-\frac{\left(9 w_{s}-8 b_{2}^{2} w_{u 2}^{2}\right)}{4 b_{1} b_{2} w_{u 2} w_{u 2}} R_{2}$ if there is integration.

C.

The denominator is given as :

$$
\varphi=48 b_{1}^{2} b_{2}^{2} w_{u}^{4}-72 b_{2}^{2} w_{u}{ }^{2} \alpha_{s} w_{s 1}-72 b_{1}^{2} w_{u}{ }^{2} w_{s 2}+81 \alpha_{s} w_{s 1} w_{s 2}>0 .
$$

We have $\alpha_{s}=1$ under no integration and $\alpha_{s}=\frac{w_{s 2}}{w_{s 1}}$ under integration. By subtracting,

$$
\begin{aligned}
& \phi_{n m}-\phi_{m}=\left(48 b_{1}{ }^{2} b_{2}{ }^{2} w_{u}{ }^{2} w_{u 2}{ }^{2}-72 b_{2}{ }^{2} w_{u}{ }^{2} w_{s 1}-72 b_{1}{ }^{2} w_{u}{ }^{2} w_{s 2}+81 w_{s 1} w_{s 2}\right)- \\
& \left(48 b_{1}{ }^{2} b_{2}{ }^{2} w_{u}{ }^{4}-72 b_{2}{ }^{2} w_{u}{ }^{2} w_{s 2}-72 b_{1}{ }^{2} w_{u}{ }^{2} w_{s 2}+81 w_{s 2} w_{s 2}\right) \\
& =\left(-72 b_{2}{ }^{2} w_{u}{ }^{2}+81 w_{s 2}\right) w_{s 1}-\left(-72 b_{2}{ }^{2} w_{u}{ }^{2}+81 w_{s 2}\right) w_{s 2} \\
& =9\left(9 w_{s 2}-8 b_{2}{ }^{2} w_{u}{ }^{2}\right)\left(w_{s 1}-w_{s 2}\right)
\end{aligned}
$$

As $\left(9 w_{s 2}-8 b_{2}{ }^{2} w_{u}{ }^{2}\right)>0$ by assumption, $9\left(9 w_{s 2}-8 b_{2}{ }^{2} w_{u}{ }^{2}\right)\left(w_{s 1}-w_{s 2}\right)>0$. Therefore, R\&D of firm 1 increases as $\phi$ falls under integration. 


\section{References}

Aaditya Mattoo, Marcelo Olarreaga and Kamal Saggi (2004) "Mode of Foreign Entry, Technology Transfer, and FDI Policy", Journal of Development Economics, Vol. 75, Issue 1, pp. 95-111.

Arrow Kenneth (1962), "Economic Welfare and the Allocation of Resources for Inventions," in R. Nelson (ed.), The Rate and Direction of Inventive Activity, Princeton, NJ: Princeton University Press.

Braun Sebastian (2008), “Economic Integration, Process and Product Innovation and Relative Skill Demand”, Review of International Economics, Vol. 16, Issue 5, pp. 864-873.

Bretschger Lucas (2001), "Labor Supply, Migration and Long-Term Development”, Open Economies Review, Vol. 12, Issue 1 pp. 5-27.

Chen Maggie (2009), "Regional Economic Integration and Geographic Concentration of Multinational Firms”, European Economic Review, Vol. 53, Issue 3, pp. 355-375.

Chen Yongmin. and Puttitanun Thitima (2005), "Intellectual Property Rights and Innovation in Developing Countries", Journal of Development Economics, Vol. 78, Issue, pp. 2 474-93.

Dasgupta Partha and Stiglitz Joseph (1980), "Industrial Structure and the nature of Innovative Activity", Economic Journal, Vol. 90, No. 358, pp. 266-293.

D’Aspremont Claude and Jacquemin Alexis (1988), "Cooperative and Noncooperative R\&D in Duopoly with Spillovers", American Economic Review, Vol. 78, No. 5, pp. 1133 1137.

Docquier Frédéric and Rapoport Hillel (2012), "Globalization, Brain Drain and Development”, Journal of Economic Literature, Vol. 50, Issue 3, pp. 681-730. 
Egger Peter and Larch Mario (2011), “An Assessment of the Europe Agreements’ Effects on Bilateral Trade, GDP, and Welfare", European Economic Review, Vol. 55, Issue 2, pp. $263-279$

Gaston Noel and Nelson Doug (2007), “The Employment and Wage Effects of Immigration: An Overview of Theory, Method and Results", GDC Working Paper, No. 6, Bond University.

Gibson John and McKenzie David (2011), "Eight Questions about Brain Drain”, Journal of Economic Perspectives, Vol. 25, No. 3, pp. 107-28.

Grubel Herbert and Scott Anthony (1966), “The International Flow of Human Capital”, American Economic Review, Vol. 56, No. 1/2, pp. 268-274.

Haaland Jan and Kind Hans (2008), "R\&D policies, Trade and Process Innovation”, Journal of International Economics, Vol. 74, Issue 1, pp. 170-187.

Haufler Andeas and Wooton Ian (2010), “Competition for Firms in an Oligopolistic Industry: The impact of Economic Integration”, Journal of International Economics, Vol 80, Issue 2, pp. 239-248.

Helpman Elhanan (1993), "Innovation, Imitation and Intellectual Property Rights", Econometrica, Vol 61, NO 6. pp. 1247-80.

Impullitti Giammario (2010), "International Competition and U.S. R\&D Subsidies: a Quantitative Welfare Analysis”, International Economic Review, Vol. 51, Issue 4, pp. $1127-1158$.

Kuhn Peter and McAusland Carol (2009), "Consumers and the Brain Drain: Product and Process Design and the Gains from Emigration", Journal of International Economics, Vol. 78, Issue 2, pp. 287-291.

Lai Edwin (1998), “International Intellectual Property Rights Protection and the rate of Product Innovation”, Journal of Development Economics, Vol. 55, Issue 1, pp. 133-53. 
Long Ngo, Horst Raff and Stähler Frank (2011), "Innovation and Trade with Heterogeneous Firms”, Journal of International Economics, Vol. 84, Issue 2, pp. 149-59.

Lundborg Per and Segerstrom Paul (2002), "The Growth and Welfare Effects of International Mass Migration”, Journal of International Economics, Vol. 56, Issue 1, pp. 177-204.

Marjit Sugata and Mukherjee Arijit (2008), "International Outsourcing and R\&D: Long-run Implications for Consumers", Review of International Economics, Vol. 16, Issue 5, pp. 1010-1022.

Migration Advisory Committee (2013), "Migrant Seasonal Workers: The impact on the horticulture and food processing sectors of closing the Seasonal Agricultural Workers Scheme and the Sectors Based Scheme", Migration Advisory Committee, UK Border Agency, London. Available on https://www.gov.uk/government/publications/seasonalmigrant-workers, accessed 14 July, 2014.

Morita Tadashi (2012), “Cost-reducing R\&D Investment, Labor Market and Trade”, Review of International Economics, Vol. 20, Issue 4, p. 821-827.

Parrotta Pierpaolo, Pozzoli Dario and Pytlikova Mariola (2014), "The Nexus between Labor Diversity and Firm's Innovation”, Journal of Population Economics, Volume 27, Issue 2, pp 303-364.

Platonova Anna and Urso Giuliana, (2010), "Migration, Employment and Labour Market Integration Policies in the European Union: Part 1", International Organization for Migration, Brussels. Available on http://www.labourmigration.eu/research/report/13migration-employment-and-the-outcomes-of-labour-market-integration-policies-in-theeuropean-union, accessed 15 July, 2014.

Rashidi Sheida and Pyka Andreas (2013), "Migration and innovation: A survey," FZID Discussion Papers 77-2013, Center for Research on Innovation and Services (FZID), University of Hohenheim, Germany. 
Saxenian AnnaLee, Motoyama Yasuyuki and Quan Xiaohong (2002), "Local and Global Networks of Immigrant Professionals in Silicon Valley", Public Policy Institute of California, San Francisco, CA, USA.

Sinha Uday and Mukherjee Arijit (2013), "Patent Protection, Southern Innovation and Welfare in a North-South Trade Model”, Economica, Vol. 80, Issue 318, pp. 248-273.

Unnikrishnan R. (2004), "Ranbaxy Tops Third World Patents List”, Financial Express, 13 December., Available on http://archive.financialexpress.com/news/ranbaxy-tops-thirdworld-patents-list/122766, accessed 9 July, 2015.

Wei Yingqi, Liu Xiaming and Wamg Chengang (2008), "Mutual Productivity Spillovers between Foreign and Local Firms in China", Cambridge Journal of Economics, Vol. 32, Issue. 4, pp. 609-31.

Zhou Dongsheng, Spencer Barbara and Vertinsky Ilan (2002), "Strategic Trade Policy and Endogenous Choice of Quality and Asymmetric Costs. Journal of International Economics, Vol. 56, Issue 1, pp. 205-32. 
Table 1: Patent applications (of residents)

\begin{tabular}{|l|r|r|r|r|r|}
\hline & $\mathbf{2 0 1 0}$ & $\mathbf{2 0 1 1}$ & $\mathbf{2 0 1 2}$ & $\mathbf{2 0 1 3}$ & $\begin{array}{l}\text { Percentage } \\
\text { change from } \\
\mathbf{2 0 1 0} \text { to 2013 }\end{array}$ \\
\hline China & 293066 & 415829 & 535313 & 704936 & $141 \%$ \\
\hline United States & 241977 & 247750 & 268782 & 287831 & $19 \%$ \\
\hline Japan & 290081 & 287580 & 287013 & 271731 & $-6 \%$ \\
\hline Korea, Rep. & 131805 & 138034 & 148136 & 159978 & $21 \%$ \\
\hline Germany & 47047 & 46986 & 46620 & 47353 & $1 \%$ \\
\hline Russian Federation & 28722 & 26495 & 28701 & 28765 & $0 \%$ \\
\hline United Kingdom & 15490 & 15343 & 15370 & 14972 & $-3 \%$ \\
\hline France & 14748 & 14655 & 14540 & 14690 & $0 \%$ \\
\hline Iran, Islamic Rep. & 11108 & 11529 & 10622 & 11305 & $2 \%$ \\
\hline India & 8853 & 8841 & 9553 & 10669 & $21 \%$ \\
\hline Italy & 8877 & 8794 & 8439 & 8307 & $-6 \%$ \\
\hline Brazil & 4228 & 4695 & 4798 & 4959 & $17 \%$ \\
\hline Canada & 4550 & 4754 & 4709 & 4567 & $0 \%$ \\
\hline Turkey & 3180 & 3885 & 4434 & 4392 & $38 \%$ \\
\hline Poland & 3203 & 3879 & 4410 & 4237 & $32 \%$ \\
\hline Source-World Develop
\end{tabular}

Source - World Development Indicators, World Bank, Last Updated: 04/14/2015 